\title{
Un techo para las mujeres. Vivienda segura para una vida libre de violencia
}

\section{POR CLAUDIA HASANBEGOVIC $(*)$}

\begin{abstract}
Sumario: I Introducción.- II. Relación entre violencia de género y vivienda.- III. Población que posiblemente llegue a los refugios y casas de medio camino.- IV. Surgimiento y desarrollo de los refugios y casas de medio camino.- V. Refugios y casas de medio camino en América Latina.- VI. Argentina y CABA: marco normativo, políticas sociales y acceso a vivienda.- VII. Conclusión y recomendaciones.VIII. Bibliografía.
\end{abstract}

Resumen: el acceso a una vivienda segura determina que las mujeres puedan dejar una relación violenta (1) y evitar la situación de calle. Este artículo presenta el análisis de 135 documentos producidos en varios países de cuatro continentes que exploran soluciones habitacionales para mujeres que escapan de la violencia doméstica. El artículo recorre el surgimiento de los refugios y casas de medio camino a nivel mundial, explorando su implementación y jurisprudencia en Argentina, y específicamente en CABA(2). En este país el Plan Nacional de Acción(3) (2017-2019) enfrenta grandes desafíos en esta materia, y las medidas de protección civiles y los amparos administrativos aparecen por ahora como las formas más sustentables de acceder a vivienda de emergencia en CABA. La conclusión

(*) Ph. D. in Social Policy, University of Kent at Canterbury, Inglaterra. MA in Women and Development, Institute of Social Studies, Holanda. Diploma in Gender, International Women University, Alemania. Abogada, UNLZ. Prof. universitaria de grado, postgrado y doctorado en Argentina (UBA) e invitada en el extranjero. Investigadora en crímenes sexuales y de género como crímenes internacionales. Mediadora (CPACF). Consultora internacional en políticas públicas sobre violencia de género. ONU-Mujeres, UNFPA, etc.

(1) El material y análisis presentados en este trabajo se refiere exclusivamente a mujeres heterosexuales víctimas de violencia doméstica por parte de sus parejas masculinas. En este trabajo nos referimos a las definiciones citadas empleando las palabras "violencia de género contra la mujer", "violencia de género"; "violencia contra la mujer"; "violencia doméstica” y “violencia de género contra la mujer en la pareja" indistintamente.

(2) CABA: Ciudad Autónoma de Buenos Aires.

(3) Abreviatura para Plan Nacional de Acción para la Prevención, Asistencia y Erradicación de la Violencia contra las Mujeres. 
formula recomendaciones para hacer más efectivas la respuesta habitacional a las mujeres.

Palabras claves: violencia de género contra las mujeres - violencia doméstica vivienda - refugios - medidas judiciales - políticas sociales

\section{A rooffor women. Safe housing for a life free from violence}

Abstract: access to safe housing determines women can leave an abusive relationship; and the lack of it, entraps women in abusive relationships or leaves them homelessness. This article presents the analysis of 135 documents from several countries, from four continents, that explores housing programs for women who escape domestic violence. The article examines the emergence of refuges and transitional housing programs worldwide, and it explores its implementation and jurisprudence in Argentina, and in CABA in particular. In this country, the National Action Plan of Combat Violence Against Women (2017-2019) faces critical challenges in this matter, and civil protective orders and administrative "amparos", appear like more sustainable forms of access to emergency housing up to now. The conclusion lays out recommendations to make housing responses for women more effective.

Keywords: gender based violence against women - domestic violence - housing refuges - judicial measures - social policies

\section{Introducción}

La violencia de género contra la mujer (4), también conocida como violencia de género, y violencia contra la mujer (5) es un problema endémico que afecta a 1 de cada 3 mujeres en el mundo entero (Krueg y otros, 2002).

(4) El Comité CEDAW en su Recomendación general 19/1992 dijo que la discriminación contra la mujer, tal como se define en el artículo 1 de la Convención, incluía "la violencia por razón de género", que es la violencia dirigida contra la mujer porque es mujer o que la afecta en forma desproporcionada, y que constituía una violación de sus derechos humanos. En 2017 establece la expresión "violencia por razón de género contra la mujer" como término más preciso, que pone de manifiesto las causas y los efectos relacionados con el género de la violencia, y la noción de la violencia como problema social más que individual, que exige respuestas integrales, más allá de aquellas relativas a sucesos concretos, autores y víctimas y supervivientes (ONU, 2017b, párrafo 1).

(5) La Convención Belém do Pará en sus artículos 1 y 2 define la "violencia contra la mujer", como "cualquier acción o conducta, basada en su género, que cause muerte, daño o sufrimiento físico, sexual o psicológico a la mujer, tanto en el ámbito público como en el privado, que incluye la violencia física, sexual y psicológica: a. que tenga lugar dentro de la familia o unidad doméstica o en cualquier otra relación interpersonal, ya sea que el agresor comparta o haya compartido el mismo domicilio que la mujer, y que comprende, entre otros, violación, maltrato y abuso sexual; b. que tenga lugar en 
Las sobrevivientes (6) de violencia doméstica (7) necesitan una respuesta policial inmediata, seguridad económica -incluyendo independizarse de su pareja violenta-, vivienda segura y accesible, apoyo significativo y monitoreo de su pareja para prevenir futuros ataques (Pahl, 1978; Dobash y Dobash, 1992). A pesar de ello, muchas sobrevivientes, especialmente las jefas de hogares con hijos/as pequeños/as, quedan en situación de calle por falta de acceso a recursos suficientes que les brinden ayuda inmediata y a largo plazo, o por el fracaso en acceder a medidas de protección ante la justicia (Hasanbegovic y otras, 2015). Se ha sostenido que: "la carencia de una vivienda adecuada puede posicionar a las mujeres en una situación más vulnerable frente a las distintas formas de violencia, y a la inversa, la violencia contra las mujeres puede conducir a la violación de su derecho a una vida adecuada" (ONU, 2005, párr. 42).

La violencia contra la mujer en la pareja es el factor con mayor peso para la iniciación de una vida en situación de calle, y; la ausencia de acceso a vivienda segura y a servicios de apoyo es el elemento clave por el cual las mujeres quedan atrapadas en relaciones abusivas. Por ello, algunas autoras sostienen que obtener vivienda segura es el factor independiente y principal más importante para prevenir la repetición de violencia en la familia (8) (Dale, 2009). Resulta indispensable brindar a las sobrevivientes de violencia de género acceso a refugios (9) y casas de medio camino (10) que les permitan estar seguras, recuperarse de los impactos

la comunidad y sea perpetrada por cualquier persona (...), y c. que sea perpetrada o tolerada por el Estado o sus agentes, dondequiera que ocurra" (OEA, 1995).

(6) Utilizamos la palabra "sobrevivientes" en vez de "víctimas", para enfatizar la fortaleza y recursos internos personales que le han permitido a la mujer victimizada resistir y escapar de dicha situación.

(7) Ley No 26.485, en su artículo 6 a) define la violencia doméstica como (...) "aquella ejercida contra las mujeres integrantes del grupo familiar, independientemente del espacio físico donde ésta ocurra, que dañe la dignidad, el bienestar, la integridad física, psicológica, sexual, económica o patrimonial, la libertad, comprendiendo la libertad reproductiva y el derecho al pleno desarrollo de las mujeres. Se entiende por grupo familiar el originado en el parentesco por consanguinidad o por afinidad, el matrimonio, las uniones de hecho y las parejas o noviazgos (...) vigentes o finalizadas."

(8) Las itálicas me corresponden.

(9) En este trabajo utilizamos indistintamente las palabras "refugio", “casa abrigo", "casa de acogida", "hogares de protección integral [HPI]" para referirnos a los dispositivos habitacionales de emergencia para mujeres afectadas por la violencia de género en la pareja.

(10) Las casas de medio camino son un paso intermedio entre una vivienda de emergencia y una vivienda estable. Va dirigido a mujeres sobrevivientes de violencia de género que necesitan cierto grado de estructura, apoyo, supervisión, educación y adquisición de habilidades o capacitación laboral, y de esa manera transitar de una situación de calle a una vivienda permanente integradas a la sociedad. "Entre los indicadores de éxito están: vivienda estable al salir del dispositivo, haber dejado una situación de violencia doméstica; mayores recursos por ingresos de empleo remunerado antes que, por subsidios" (Novac y Otros, 2009, pp. 8 y 11). 
de la violencia e independizarse económicamente de sus agresores, en un marco más amplio de políticas públicas de acceso a vivienda permanente, capacitación laboral y trabajo, sumado a la intervención eficiente de la justicia y la policía para frenar a sus agresores, y evite la ocurrencia de nuevos hechos de violencia (Hasanbegovic, 2018).

Este artículo explora el estado del arte de los estudios, protocolos de funcionamiento y evaluaciones sobre dispositivos habitacionales de emergencia para mujeres afectadas por la violencia de género, en la modalidad de violencia doméstica, que permiten identificar la necesidad de los mismos, y qué características les son necesarias para ser de utilidad a las mujeres. Este trabajo utiliza como caso de estudio la situación existente en Argentina en materia de violencia de género y vivienda, principalmente en la CABA, donde la principal forma de acceso a vivienda de emergencia para las mujeres sobrevivientes aparece gestionada por la Justicia Nacional en lo Civil, mediante medidas cautelares y la Justicia Contencioso Administrativa y Tributaria de la Ciudad (en adelante Justicia CAyT), a través de acciones de amparo. El artículo concluye con una reseña de lo presentado y recomendaciones para hacer más efectivas las respuestas habitacionales en este campo, en especial en la Argentina y la Ciudad de Buenos Aires.

Este trabajo presenta el análisis de la sistematización de documentos que hemos recopilado sobre: a) la relación entre violencia de género en la pareja y vivienda, y b) las respuestas habitacionales para las sobrevivientes, conocidas como refugios y casas de medio camino (11). Los documentos proceden de América, Europa, Oceanía y África y en un 68\% de países de habla inglesa (12) (Canadá, Estados Unidos, Australia, Irlanda y Gran Bretaña)(13). Para hallar los documentos buscamos por Internet 20 palabras claves, en 21 portales especializados y realizamos 70 contactos personales por páginas web y correos electrónicos. En total sistematizamos y analizamos 135(14) ensayos, protocolos de refugios y de casas de medio camino, anexos de protocolos, y evaluaciones de dichos dispositivos.

(11) Entre octubre de 2013 y marzo de 2014 realicé para el Instituto Nacional de las Mujeres de la República Oriental del Uruguay -INMUJERES - una consultoría sobre casas de medio camino en vistas a la creación de ese dispositivo en dicho país. Agradezco a INMUJERES haberme contratado para dicha labor y en especial, a la Lic. Karina Ruíz, su directora de la División de Violencia Basada en el Género por la entrevista concedida para este artículo. Este trabajo, en parte, se basa en los documentos recopilados y análisis efectuados para aquella ocasión.

(12) Todas las traducciones al idioma castellano fueron realizadas por la autora.

(13) Dos documentos están escritos en idioma italiano y un documento en portugués.

(14) Por razones de espacio solamente se presentan en la bibliografía aquellos documentos que son citados en el texto. 
Como caso de estudio, sumamos información específica de Argentina sobre violencia doméstica, estadísticas, hogares de protección integral, y jurisprudencia de la CABA en la materia. La metodología se completó con entrevistas y observaciones en una casa de medio camino en la CABA, y a mujeres que dirigieron refugios y/o que fueron residentes de estos dispositivos.

\section{Relación entre violencia de género y vivienda}

En New South Wales, Australia, la institución nacional que asiste a las personas en situación de calle (SAAP), dice que: "La violencia doméstica ha sido la principal causa invocada a lo largo de 25 años por mujeres solteras y mujeres con hijos/as para utilizar los servicios del Supported Accommodation Assistance Programme (SAAP)" (AIHW citada en Edwards, 2004, p. 8). En el mismo sentido, estudios realizados en Canadá, Estados Unidos, Australia, Irlanda, en varios países del cono sur y en la $\mathrm{CABA}$, encontraron que la vivienda es una preocupación significativa y que carecer de ella puede forzar y/o condicionar a las mujeres a regresar a una relación abusiva (Tutty, 2006; Correia y Melbin, 2005; Gregory, 2001; O'Connor y Wilson, 2004; Ricciardi, 2010; ELA, 2012; Hasanbegovic y otras, 2015).

La vivienda, ya sea "de emergencia, de medio camino o permanente", es un punto fundamental para ayudar a las sobrevivientes de violencia de género a dejar definitivamente la relación abusiva. La literatura especializada indica que cuando las mujeres dejan los refugios donde estuvieron alojadas, muy a menudo se encuentran con la falta de vivienda y de manutención, enfrentándose a una vida en la pobreza para ellas, sus hijos e hijas (Ciapessoni, 2014) o bien, acceden a viviendas y apoyo financiero inadecuados que las obligaron a elegir entre quedarse en situación de calle o regresar con su pareja abusiva (15).

Entre la literatura revisada hallamos que en Irlanda las mujeres en situación de calle comúnmente son ex residentes de refugios para mujeres maltratadas que no lograron encontrar vivienda segura y adecuada al egresar de los mismos (O'Connor y Wilson, 2004). Por ello, las casas de medio camino constituyen un tipo de servicio fundamental para continuar el trabajo que realizan los refugios, facilitar la recuperación de las mujeres de los hechos traumáticos vividos, y consolidar su empoderamiento económico.

Sostienen varias autoras que tanto en Gran Bretaña como en los Estados Unidos y Australia la provisión de refugios y de casas de medio camino ha sido similar

(15) Esto fue corroborado por las mujeres entrevistadas, quienes, en ocasiones, habían regresado con sus agresores para evitarles a sus hijos/as las incomodidades y peligros — por ataques de otros niños con vidrios- de residir en un refugio. 
y ha constituido la principal estrategia para cubrir las necesidades inmediatas de las mujeres y de sus hijas e hijos cuando escapan de la violencia doméstica. Sin embargo, la escasez de vivienda adecuada y accesible a largo plazo constituyen un problema (Dobash y Dobash, 1992; Commonwealth Australia, 2000; ELA, 2012), y "dicha escasez, en muchos casos obligó a las mujeres a volver a su antigua vivienda con su agresor" (Commonwealth Australia, 2000, pp. 34-35). La falta de acceso a un ingreso decente y a una vivienda segura constituyen los factores de riesgo más importantes para quedar en situación de calle para las mujeres sobrevivientes de violencia doméstica (Dobash y Dobash, 1992; O'Connor y Wilson, 2004; Tutty y Otros, 2008; Sullivan y otros, 2003; Gregory, 2001; Edwards, 2004; Dale, 2009), quienes, además, se hallan sin posibilidades para trabajar, y sufren discriminación (16) (Mbilinyi y Kreiter, 2013). Dejar una pareja masculina proveedora puede implicar para las mujeres la posibilidad de enfrentar una vida de pobreza y de incomodidades para ella y sus hijas e hijos (Hasanbegovic y otras, 2015; Ricciardi, 2010).

Muchas veces las sobrevivientes que han pasado por refugios y luego por casas de medio camino no han logrado obtener ingresos económicos adecuados para acceder a una vivienda estable, viéndose obligadas a optar entre la situación de calle para ellas y sus hijos e hijas, o volver con su agresor (Dale, 2009). Ello es posible por la intersección (17) de numerosas formas de discriminación que afectan a las mujeres por ocupar diversas posiciones de género, de clase y étnico-racial, tales como: ser mujeres pobres, con hijos/as a cargo, tener bajo nivel de escolaridad, no contar con redes familiares y sociales de apoyo (por ser migrantes o por venir de familias donde hubo o hay violencia de género, por ser huérfanas, etc.), hallarse en un contexto de discriminación laboral de género, bajos salarios asignados para trabajos tradicionalmente femeninos, mayor presencia de mujeres en los trabajos informales o de tiempo parcial, la brecha salarial entre hombres y mujeres, la violencia de género contra niñas y adolescentes que muchas veces las obliga a escaparse de sus hogares o bien unirse a parejas para alejarse de los mismos, sin

(16) Conforme al artículo 1 de la Convención Internacional para la Eliminación de toda forma de discriminación hacia la mujer —CEDAW, por su sigla en inglés-, la expresión "discriminación contra la mujer" denotará toda distinción, exclusión o restricción basada en el sexo que tenga por objeto o resultado menoscabar o anular el reconocimiento, goce o ejercicio por la mujer, independientemente de su estado civil, sobre la base de la igualdad del hombre y la mujer, de los derechos humanos y las libertades fundamentales en las esferas política, económica, social, cultural y civil o en cualquier otra esfera. (Constitución Nacional, artículo 72 inciso 22 y Convención CEDAW, ratificada por ley 23.179 de 1985).

(17) Este enfoque se denomina interseccionalidad, e "implica aprehender la realidad de las personas y de los grupos sociales, desde una concepción holística e integradora, que debe incidir en el diseño e implementación de las políticas públicas si se pretende promover el desarrollo en igualdad" (CEPAL, 2016, p. 22). 
tomar en cuenta que ingresan a una relación violenta, entre otras. Los agresores se aprovechan de las circunstancias de vida desfavorable de cada mujer e incluso las empeoran con actitudes tales como volver a agredirlas, dejar de pagar la renta o la hipoteca, poniéndolas en riesgo de desalojos, o hacerles perder el trabajo, obstaculizarle sus estudios, y robarle sus ahorros (Sharp, 2008). En este sentido, el abuso económico fue expresado por las sobrevivientes como una violencia continuada, que refuerza las otras formas de violencia (Dobash y Dobash, 1992; Frederic y Lizdzt, 2003; Sharp, 2008). Los agresores hacen todo esto, aún después de separados, para castigar y mantener el control sobre sus víctimas.

\section{Población que posiblemente llegue a los refugios y casas de medio camino}

Las proveedoras de servicios en dispositivos habitacionales enfatizan la necesidad de reconocer que para las mujeres de las clases más desfavorecidas existe un enorme salto entre sus posibilidades de ser empleadas y las ofertas de trabajo, y recomiendan encarar programas que solucionen sus bajos niveles de educación formal y marginalización del mercado laboral. Ellas recomiendan que "el trabajo remunerado sostenible" sea concebido como un proceso, y no como un evento (18), y que se reconozca que para aquellas mujeres con múltiples barreras para obtener empleo remunerado la asistencia social no es temporaria (Dale, 2009). En el contexto sudamericano, una investigación concluyó que

De las experiencias de las mujeres surge claramente lo importante que es para ellas saber a dónde van a ir si deciden romper con el círculo de la violencia (...) la falta de una solución para esta situación puede ser determinante para decidir continuar en la relación o no. Sólo al estar frente a una enorme crisis o frente a violencia extrema, casi con riesgo para su vida, hace que las mujeres salgan de los lugares que habitan sin una alternativa presente. (...) la desigualdad en el acceso a la propiedad y al mercado de trabajo combinada con la existencia de un sistema patriarcal que expone a las mujeres a la violencia de género, las deja en condiciones de inferioridad para el desarrollo de sus vidas. Estos son los desafíos que hay que enfrentar para lograr un cambio, para que tenga una opción real para dejar las relaciones violentas. Para ello es vital ofrecerles un lugar donde vivir, sino muchos de los esfuerzos resultarán en vano (Ricciardi, 2010, p. 18).

Estudios empíricos en la CABA (Hasanbegovic y Otras, 2015) obtuvieron resultados similares y sugieren que la población que con mayor probabilidad buscará

(18) Las itálicas me corresponden. 
ayuda en estos dispositivos habitacionales provendrán de los estratos socioeconómicos desfavorecidos, con bajo nivel de educación formal, sin redes familiares y sociales a quienes poder acudir, y que experimenten un mayor nivel de consecuencias psicológicas, lo cual puede contribuir a retardar su inserción laboral. Se trata de mujeres que necesitarán apoyo intensivo, flexible y creativo para poder salir de las consecuencias de la violencia, y también, de la pobreza estructural y de la falta de redes sociales y familiares de apoyo. El mayor desafío para que las casas de medio camino tengan un resultado exitoso será el tiempo de estadía necesario para que las mujeres puedan completar su educación formal y capacitación laboral y encontrar trabajos remunerados, guarderías adecuadas - si tienen hijos/as pequeños a cargo- $-\mathrm{y}$ viviendas accesibles (disponibilidad de garantías y precios).

\section{Surgimiento y desarrollo de los refugios y casas de medio camino}

En los primeros años de la década de 1970, surgen en Inglaterra, Estados Unidos, Irlanda, Canadá y Australia los refugios para mujeres maltratadas. Éstos fueron creados primeramente por las mismas sobrevivientes y por el movimiento de mujeres en general, ocupando casas deshabitadas. Con el tiempo, estos refugios recibieron apoyo económico de particulares y progresivamente de los Estados. Los refugios fueron extendiéndose al resto del mundo como "modelo de respuesta en violencia doméstica", especialmente a través de las recomendaciones internacionales de las Naciones Unidas a través del Comité de la CEDAW y por la Plataforma de Acción de Beijing 1995 (19), entre otros.

En Inglaterra - y en el mundo-, el surgimiento del movimiento de mujeres maltratadas (battered women's movement) y de los refugios se remonta a una marcha de mujeres con sus hijas e hijos en el barrio londinense de Chiswick, en 1972. La manifestación buscaba bajar el precio de la leche, objetivo en el que fracasaron; pero, sin proponérselo al reunirse para organizar la marcha, dieron nacimiento a un movimiento mundial contra la violencia doméstica (Dobash y Dobash, 1980). Las mujeres - todas ellas de clases populares- comenzaron a reunirse periódicamente para pedir la baja del precio de la leche. Ello rompió el aislamiento al que las tenían sometidas sus agresores y, al socializar sus experiencias de violencia, rompieron también con la culpa que sentían y generaron lazos de solidaridad entre ellas, lo que les permitió dejar a sus agresores. Las mujeres ocuparon casas abandonadas, las que transformaron en casas para mujeres, donde toda mujer que escapaba de una situación de violencia obtenía cobijo. Al poco tiempo de abierto el refugio, el mismo tenía su capacidad colmada, con mujeres y sus hijas

(19) Recomendación general número 19/1992 del Comité CEDAW (ONU, 1992), párrafo 24, k, y Plataforma de Acción de Beijing, objetivo estratégico D.1., Adoptar medidas integradas para prevenir y eliminar la violencia contra la mujer, medida 125 (ONU, 1995-2014). 
e hijos residiendo en el mismo; y con más mujeres pidiendo ingresar (Dobash y Dobash, 1992).

Un aspecto de suma importancia en el movimiento de refugios para mujeres y sus hijas e hijos es el acceso a casas seguras donde residir al dejar a sus agresores y en las que se promueva la seguridad de la sobreviviente y se satisfagan sus necesidades (Frederick y Lizdas, 2003), brindando a las mujeres todo aquello que el maltrato les quitó. Es por ello que el movimiento de mujeres maltratadas ha dedicado mucho de su capital político estimulando la provisión de servicios para las sobrevivientes, para que puedan recuperar completamente su seguridad, libertad y autonomía (Dobash y Dobash, 1992; Frederick y Lizdas, 2003; Pahl, 1978).

En Australia, luego de la celebración del Día Internacional de la Mujer de 1974, un grupo de mujeres abrió el primer refugio para mujeres maltratadas llamado $E l$ sie Women and Children's Refuge, el cual actualmente es miembro del Movimiento de Refugios para Mujeres de Nueva Escocia Occidental (Edwards, 2004).

Por su parte, el programa de casas de medio camino en Australia brinda alojamiento entre 12 a 18 meses a personas que están en situación de calle o en peligro de estarlo. Este programa fue fundado por el National Affordable Housing Agreement y el Homelessness Support Program, y se enmarca en las políticas de apoyo a las personas en situación de calle conocido como el Supported Accommodation Assistance (SAAP) (Commonwealth Australia, 2008).

En Canadá, en 1975 existían 18 refugios. Desde la mitad de la década de 1970 la Agencia Canadiense para Personas Sin Techo financió aproximadamente 320 refugios y casas de medio camino lo que llevó a que "entre 1991-1994 Canadá duplicó la cantidad de casas de medio camino. Para el año 2004 existían en total 543 refugios y casas de medio camino (...)" (CMHC, 2007). En la actualidad los refugios continúan siendo la principal forma de protección(20) para mujeres y niñas y niños víctimas de violencia doméstica (Tutty, 2006). Sin embargo, debido a los recortes en ayuda social del Estado canadiense desde mediados de la década de 1990 en adelante, existían solamente 75 casas de medio camino en todo el país, de las cuales solamente 8 brindan servicios a mujeres sobrevivientes de violencia doméstica con sus hijas/os; y en ningún caso es específico para ellas (CMHC, 2009).

En Estados Unidos, los refugios "datan de los primeros años de la década de los años 1970" (Dobash y Dobash, 1992). En 1989 existían 1.200 refugios en los Estados Unidos que brindaban cada año alojamiento a 300.000 mujeres y sus hijas e hijos. Si bien los servicios que brindan estos dispositivos no son uniformes,

(20) Las itálicas me corresponden. 
en general incluyen: alojamiento seguro y alimentación; programas de apoyo a mujeres y sus hijas e hijos; guardería; asistencia legal y capacitación laboral. Debido a la falta de vivienda segura y accesible para las mujeres que completaban su estadía en el refugio y ante la imposibilidad de regresar a sus hogares, los refugios pasaron a brindar casas de medio camino a las víctimas, y entre los años 1994 y 2004 se crearon más de 500 programas de este tipo para mujeres víctimas de violencia doméstica y por otros motivos (CMHC, 2009). No obstante, los programas han sido criticados por estigmatizar y ser muy onerosos, sugiriendo que el dinero empleado en ellos sería mejor aprovechado en construir viviendas sociales. También se sostiene que las casas de medio camino fueron creadas sin la participación y voz de las mujeres maltratadas, lo cual es especialmente problemático a la luz de los estudios existentes que indican los beneficios de utilizar las necesidades de las consumidoras como guía para brindar servicios (Sullivan y otros, 2003).

En Irlanda los primeros refugios fueron abiertos entre 1974 y 1975 en Dublin, Limerick, y Cork, siendo su principal objetivo brindar vivienda segura, información y servicios de apoyo para que las mujeres pudieran acceder a sus derechos y a una vida libre de violencia (O'Connor y Wilson, 2004). Éstos se transformaron también en activistas promoviendo cambios en las políticas sociales y legales del país, cuya impronta comenzó a divisarse durante la década del 90 a través una gran variedad de respuestas, en particular de grupos que brindaban servicios de apoyo por fuera de los refugios. En la actualidad SONAS Housing Association (O'Connor y Wilson, 2004) es el programa que hemos identificado como buena práctica en materia de dispositivos habitacionales, enfoque de trabajo, y eficiencia en ayudar a las mujeres a alcanzar una vida independiente y libre de violencia.

En España, el origen de los refugios y casas de medio camino, allí conocidos como casas de acogida y pisos tutelados, se remonta en las políticas de lucha contra la violencia doméstica y de género, en particular desde la sanción de la ley integral No $1 / 2004$ contra la violencia de género. Estos dos recursos habitacionales constituyen recursos creados por las comunidades autónomas y son administrados por los ayuntamientos de los municipios para acoger y proteger a las mujeres que han sufrido algún tipo de violencia de género y a sus hijos e hijas. En estos dispositivos toda mujer puede recibir asistencia, asesoramiento jurídico y social y apoyo psicológico, y "la asistencia a los servicios es obligatoria, se debe pagar un alquiler, y solamente pueden ingresar mujeres con hijas e hijos" (Ciudad Autónoma de Ceuta, 2013, p. s/n). Las mujeres que ingresan al programa deben cumplir normas de convivencia, evitar enfrentamientos con el supuesto agresor, y llevar a cabo el trabajo de los equipos técnicos con las mujeres. Cada ayuntamiento tiene un presupuesto anual dedicado a estos. 
El tipo de trabajo que se realiza con las mujeres en las casas de acogida y pisos tutelados de España incluye la recuperación de las consecuencias de la violencia de género y promover la integración de la mujer en el entorno laboral y social de forma activa según sus capacidades. Se vela por la escolarización de las y los niñas/os y se asesora a las madres en cómo mejorar la educación familiar de sus hijas e hijos, en aquellos casos que éstas lo necesiten. La duración del régimen de acogida de las mujeres es diferente según valoración del equipo técnico que asesora las usuarias (Ciudad Autónoma de Ceuta, 2013).

\section{IV.1. ¿Qué pasó con los objetivos emancipatorios de los refugios?}

El objetivo primordial de las mujeres que escapan una relación íntima abusiva es lograr una vivienda segura, recuperarse de las secuelas que les dejó la violencia, obtener mayor control sobre sus vidas e independizarse económicamente de su agresor. Los refugios y casas de medio camino facilitarán a las sobrevivientes estos objetivos dependiendo del tipo de política pública en el que esté enmarcado cada dispositivo. Si se trata de políticas sensibles al género o de políticas ciegas al género o familiaristas (INMUJERES, 2008), es posible que consigan las sobrevivientes mayores niveles de autonomía en el primer caso, y difícilmente sean exitosas en los últimos dos tipos de políticas.

Los primeros refugios fueron abiertos por las propias sobrevivientes y reclamaron con el tiempo asistencia al Estado, constituyendo demandas de naturaleza política, ya que exigían un cambio de paradigma. A comienzos de los años 1980 en los países con Estados de Bienestar comenzaron a incluir la problemática de la violencia doméstica entre sus políticas habitacionales; por lo general, desde perspectivas individualistas, para las personas sin techo, y, por lo tanto, ajenas al sentido político del movimiento de mujeres maltratadas. Paralelamente continuaron existiendo respuestas habitacionales feministas que, en Gran Bretaña, reconocen su origen histórico en las primeras Women's Aid, que si bien reciben aportes del Estado mantuvieron su independencia de criterio, en una constante tensión.

Los resultados de la aplicación de los distintos tipos de enfoques en las políticas habitacionales para las mujeres sobrevivientes de violencia doméstica han sido variados, y señalan que aquellas políticas habitacionales familiaristas, o focalizadas en la situación de calle, han resultado negativas para muchas mujeres (y sus hijos e hijas). Así, en Irlanda se ha enviado a las familias monomarentales (21) sobrevivientes de violencia de género a hospedajes (Bed and Breakfasts) que fueron

(21) Elegimos el término monomarentales en vez de monoparentales porque en los hogares con jefatura única, aquellos con jefatura femenina son porcentualmente mucho mayores a aquellos con jefatura masculina (Hasanbegovic y otras, 2015). 
utilizados como casas de medio camino (O'Connor, 2006) (22). Estos dispositivos no responden a la necesidad de "vivienda segura", ni proveen servicios de apoyo. $\mathrm{Y}$, según dan cuenta varios estudios, las mujeres y sus hijas e hijos han sufrido retraumatizaciones por estar en contacto con otros hospedados, varones, muchas veces violentos, o hasta haber sido acosadas sexualmente por los administradores de dichos hospedajes (O'Connor, 2006; O'Connor y Wilson, 2004). Por el contrario, todos los refugios y casas de medio camino provistos por las Women's Aid de Inglaterra e Irlanda, brindan servicios específicos ajustados a las necesidades de las mujeres y de sus hijas e hijos, al tiempo que desarrollan actividades de lobby político para modificar legislaciones y estructuras que influyen en la persistencia de la violencia de género contra las mujeres y sus hijas e hijos.

\section{IV.2. La injusticia de verse obligada a escapar}

Las mujeres sobrevivientes de violencia de género en la pareja que pasaron por refugios y casas de medio camino han manifestado muchas veces su enojo y malestar por tener que abandonar sus viviendas luego de ser agredidas, mientras sus agresores continuaron utilizando el hogar familiar (Olson, 2007; O'Connor y Wilson, 2004; Hasanbegovic y otras, 2015). Otras mujeres, quienes fueron el mayor o único sostén económico de la familia expresaron que ellas tenían derecho a quedarse en sus hogares, y no tendrían por qué irse "porque sus agresores no pudieran controlar sus impulsos" (Edwards, 2004). En Cuba durante los años 1990, profesionales y vecinos/as rechazaban la idea de que las mujeres agredidas por sus parejas masculinas debieran dejar sus viviendas para estar a salvo de sus agresores y sugerían que ellas debían permanecer en sus hogares, ser protegidas por la comunidad y sus agresores debían ser arrestados y sancionados (23). Desde comienzos del siglo XXI existe una tendencia creciente a identificar y denunciar la injusticia que representa la situación descripta y en Australia, por ejemplo, se promueven políticas de Stay at Home Safe (quedarse en casa a salvo) (Commonwealth of Australia, 2008; Olson, 2007; Gregory, 2001; Edwards, 2004). Resulta indispensable para que las mujeres puedan permanecer en sus casas en forma segura:

Que el agresor sea obligado a dejar el hogar por la policía; que la justicia lo mantenga fuera del hogar a lo largo del tiempo; que se resuel-

(22) Lo mismo sucede en la CABA, donde "subsisten refugios para víctimas de violencia doméstica con paradores para mujeres en situación de calle, que muchas veces tienen como residentes a mujeres que quedaron en esa situación por escapar de la violencia de género en la pareja" (Hasanbegovic y otras, 2015).

(23) Durante los talleres que conduje sobre Violencia Doméstica y Derechos Humanos entre octubre 1999 y febrero 2000 en La Habana, entre 150 participantes entre profesionales de la salud, abogados/as, religiosas y miembros de la comunidad. 
van los temas de seguridad inmediatos y a largo plazo para la mujer y sus hijos/as, y que se les brinde apoyo [financiero, social y emocional] a largo plazo, y se prevengan futuros hechos de violencia (Edwards, 2004, p. 52).

Estas condiciones básicas para este tipo de políticas, sin embargo, parecen difíciles de alcanzar debido a la ineficacia del sistema judicial y policial para frenar a los agresores y proteger a las sobrevivientes y prevenir nuevas situaciones de violencia, estos dispositivos habitacionales deben continuar, y las políticas Stay at Home Safe se parecen más a expresiones de deseos que a opciones concretas para las mujeres (O'Connor y Wilson, 2004; Vargas Escobar, y otros, 2012).

\section{IV.3. Institucionalización y profesionalización de los refugios}

Se ha sostenido que los refugios para mujeres fueron mutando por un proceso de institucionalización y de profesionalización que progresivamente desnaturalizó los principios feministas que guiaron su funcionamiento. En Gran Bretaña este proceso se ha denominado cooptación por parte del Estado, y se concreta mediante la financiación y/o administración de los refugios a través de las Housing Associations (Asociaciones de Vivienda), donde los criterios de admisión y pago del alquiler en el refugio, por ejemplo, están dados por el Estado(24).

La institucionalización y profesionalización de los refugios y, en definitiva, del movimiento de mujeres maltratadas, han sido ampliamente discutidos entre las activistas que crearon los primeros refugios. Una versión sobre lo que sucedió dice:

(...) Poco después que las feministas se durmieran, el profesionalismo oficial infiltró los programas de asistencia a mujeres maltratadas, trayendo más y nuevas jerarquías (...) que debilitaron los esfuerzos de las feministas de erradicar las raíces que causaban la violencia doméstica. El ejercicio del poder en forma conjunta y horizontal entre empleadas fue rápidamente descartado y prácticas éticas que incluían las voces y experiencias de las mujeres maltratadas, capacitación básica sobre la dinámica de la violencia doméstica, y el poder de las experiencias compartidas entre las mujeres fueron desaprobadas (...). En los refugios oficiales comenzaron a aparecer directoras sin capacitación para decirle a las trabajadoras de los refugios (...) que no eran tan importantes como las profesionales universitarias (...). Las mujeres maltratadas

(24) De esa manera "el Estado puede determinar si mujeres migrantes con residencia transitoria en el país podrán o no podrán ingresar al refugio, ya que el pago del alquiler y la manutención para residir en el mismo dependerá de los subsidios habitacionales a los que puede acceder una mujer según el estatus de ciudadanía o residencia que tenga" (Hasanbegovic, 2010, pp. 105-107). 
que buscaban refugio fueron mantenidas en cautiverio de las reglas de convivencia que nunca terminan y que fueron instituidas por las profesionales oficiales sordas a los ruidos de las fundadoras originales. Muchas de las casas seguras ahora se parecen más a las prisiones, o a hosterías sociales, y les impiden su entrada a las mujeres con discapacidades de todas las razas, edades, clases, y religión y a las mujeres de grupos étnicos. Se refieren a las víctimas como locas y golpean con látigos a las defensoras de las víctimas que se atreven a cuestionar la tarea profesional del amo (...) (Gaddis, citada en Koyama, 2006, p. 6).

Las feministas radicales ven la institucionalización y profesionalismo del movimiento como un proceso continuo de despolitización(25), alimentado por la contraofensiva patriarcal o backlash y la cooptación por parte de los Estados para volverlo funcional a sus intereses políticos (Koyama, 2006). Además:

(...) cuando todos los esfuerzos se realizan para "mejorar" las condiciones de vida de las mujeres maltratadas, y esto se transforma en el único objetivo, la visión política y motivación de atacar la causa de la dominación masculina se sublima (...) Desaparece lo político de la violencia doméstica y se naturaliza como parte de lo que parece ser un panorama social sin modificar y que no puede ser modificado (Meyer, citada en Koyama, 2006, pp. 6-7).

Ante ese escenario, Koyama propone combatir la institucionalización con una hiper-institucionalización que permita contrarrestar mediante la creación de mecanismos de transparencia, responsabilidad y control de los equipos de trabajo de los refugios, los abusos de poder que se producen dentro de estos dispositivos, tales como hostilidad y paternalismo hacia las sobrevivientes, ya que se hablaría de hermandad entre mujeres, pero se pasaría por alto las diferencias de intereses de las mujeres, y se las silenciaría al no permitir su participación en el establecimiento de normas y políticas del refugio (Koyama, 2006).

\section{Refugios y casas de medio camino en América Latina}

La irrupción de los derechos de las mujeres en la agenda internacional a comienzos de los años 1990's tuvo su impacto en los países de América Latina mediante recomendaciones de creación de refugios, también llamados centros de acogida y casas de medio camino como parte de las respuestas a la violencia doméstica contra las mujeres. En nuestra región, en 1994 se aprobó la Convención

(25) Una definición de este tipo de despolitización dice que es: “un proceso de reestructuración que dirige su atención afuera (y recrea el conocimiento sobre) el sexismo, la dominación masculina, el patriarcado, y la opresión femenina" (Meyer, citada en Koyama, 2006, p. 6). 
Interamericana para Prevenir, Sancionar y Erradicar la Violencia contra la Mujer -Belém do Pará-, que en su artículo 8 inciso d) establece que los Estados proveerán "refugios".

En el Uruguay, el primer refugio, allí llamado "casa de breve estadía para riesgo de vida", fue creado en 2002 de la mano de la primera ley de prevención de la violencia doméstica de ese país. En especial, desde el año 2005 en adelante, Uruguay fue incrementando el abanico de respuestas a las sobrevivientes de violencia doméstica y las soluciones habitacionales para ellas y sus hijas/os. En la actualidad existen

(...) casas de breve estadía para riesgo de vida, donde la mujer puede estar hasta 1 mes; un centro de estadía transitorio, con residencia hasta 9 meses, la casa de medio camino donde puede vivir hasta 12 meses, y una serie de subsidios habitacionales y garantías para que las mujeres puedan alquilar su propia vivienda. La idea es no institucionalizar y que en lo posible las mujeres obtengan el subsidio de alquiler por dos años. Pero, todo es flexible y se estudia el caso a caso (26) (Ruiz, 2018).

En la revisión de protocolos y evaluaciones de funcionamiento de refugios y casas de medio camino de Argentina (27), Chile, Ecuador y Uruguay encontramos que los enfoques de su trabajo son la perspectiva de género y de derechos humanos (DGM, 2011a, 2011b; SERNAM, 2013; INMUJERES, 2013; Ávila Jacome, 2012 citados en Hasanbegovic, 2014). Trabajar desde la perspectiva de género permite identificar las causas estructurales de la violencia de género contra la mujer, la asimetría de poder y consecuencias en la mujer y en las mujeres, como clase, en general. Por otra parte, el enfoque de derechos humanos se basa en el eje de derechos y marco normativo que ve a las mujeres que sufren violencia como sujetos de derecho y al Estado como obligado a garantizarle su derecho a una vida libre de violencia.

Entre los principales objetivos del trabajo con las mujeres en los refugios y casas de medio camino que surgen de la lectura que efectuamos de los protocolos, se enumeran: brindar un alojamiento seguro y asistir a las mujeres en la recuperación de su autonomía, en vistas a un egreso hacia una vida independiente y libre de violencia de género. Estos dispositivos habitacionales se diferencian entre sí según sean administrados por ONGs o por el Estado. Si bien ambos obedecen a los mismos principios, aquellos dirigidos por ONGs de mujeres (por ejemplo, en

(26) Comunicación de la autora con la Lic. Karina Ruíz, directora de la división de violencia basada en el género del Instituto Nacional de las Mujeres, 01/09/2018.

(27) En Argentina se revisó el protocolo de funcionamiento de casas de medio camino de la Ciudad de Buenos Aires. 
México y en Nicaragua) cuentan con activismo social en redes regionales de refugios, procurando cambios sociales hacia la erradicación de la violencia de género, y acerca de la necesidad de crear mayor cantidad de refugios, de obtener más financiamiento y de mejorar las legislaciones (Vargas Escobar y Mejía Padua, 2012). Algunos de estos dispositivos responden a políticas familiaristas, reproduciendo los estereotipos sexuales tradicionales en las capacitaciones laborales y buscan re-educar a las mujeres en su rol de madres, en tanto que otras respuestas habitacionales surgen de la aplicación de políticas género sensitivas (28). En este último tipo de políticas se enmarcan los dispositivos habitacionales para mujeres sobrevivientes de violencia de género en el Uruguay.

A continuación, daremos información en mayor nivel de detalle referida a la República Argentina, con foco en la CABA.

\section{Argentina y CABA: marco normativo, políticas sociales y acceso a vivienda}

Las estadísticas en nuestro país señalan que "cada 30 horas muere una mujer por femicidio en la Argentina, en sólo 8 años (desde el 2008 al 2015) 2.094 mujeres fueron asesinadas (...)" (CNM (29), 2016, p. 29) y "durante los dos primeros años de funcionamiento de la Línea 144 se recibieron 60.543 llamadas relativas a casos de violencia de género (30)" (CNM, 2016, p. 37). En el período 2013-2018, los organismos estatales que documentan los casos de violencia contra la mujer han registrado 576.360 casos, en los cuales el $82,1 \%$ de los agresores eran ex parejas o parejas de las mujeres afectadas (INDEC (31), 2019). Específicamente en la Ciudad de Buenos Aires, según surge de los datos estadísticos para el período 2008-2017, la Oficina de Violencia Doméstica de la Corte Suprema de Justicia de

(28) Las políticas género sensitivas "toman en cuenta las necesidades de mujeres y hombres, introduciendo cambios en los desequilibrios de poder, y buscan la articulación de la esfera pública y la esfera privada para redistribuir la carga doméstica, modificar las condiciones de inserción de las mujeres en el mercado laboral, impulsar procesos que favorezcan el empoderamiento y la participación en la toma de decisiones y, en general, garantizar las condiciones para el pleno ejercicio de los derechos humanos de las mujeres" (INMUJERES, 2008).

(29) CNM: Consejo Nacional de la Mujer.

(30) El Comité CEDAW en su recomendación general número 19 (1992), aclaró que la discriminación contra la mujer incluía la "violencia dirigida contra la mujer porque es mujer o que la afecta en forma desproporcionada", y en su recomendación general número 35 (2017b) establece que violencia de género contra la mujer es un término más preciso que pone de manifiesto las causas y los efectos relacionados con el género de la violencia (...) (párrafos $1^{\circ}$ y 9). En este trabajo utilizamos violencia de género contra la mujer, violencia en la pareja, violencia contra la mujer, y violencia doméstica en forma indistinta.

(31) INDEC: Instituto Nacional de Estadística y Censos. 
la Nación(32) "atendió 80.078 casos, de los cuales el 89\% correspondía a mujeres, afectadas en un $91 \%$ por agresores masculinos, con quienes en un $83 \%$ existía un vínculo de pareja" (OVD, 2018a).

El acceso a vivienda para mujeres afectadas por la violencia de género se enmarca a nivel nacional y en la CABA en particular, dentro de un amplio marco normativo y convencional que establece garantías, derechos, obligaciones de políticas públicas en la provisión de vivienda de emergencia segura para mujeres sobrevivientes de violencia doméstica, y de vivienda digna para las personas en situación de calle. En la CABA, ante la fragilidad y discontinuidad en las políticas sociales y el incumplimiento del Poder Ejecutivo en la provisión de los recursos habitacionales adecuados, muchas sobrevivientes acceden a la vivienda mediante acciones judiciales. Éstas se entablan: a) en la Justicia Nacional en lo Civil obteniendo la Exclusión del Hogar del agresor que va acompañada de la Prohibición de Acercamiento, y presupone el estar residiendo en una vivienda a la que se puede regresar(33); y b) por medio de Amparos Habitacionales, en la Justicia CAyT, cuando han quedado en situación de calle y no pueden regresar a la residencia en la que vivían con su agresor. Cuestiones de clase social y de etnia-raza (nacionalidad, situación migratoria, etc.) aparecen asociadas a la problemática de la violencia de género y de vivienda, expresándose en el tipo de medida judicial que solicitan: Exclusiones del Hogar, mujeres de estratos sociales medios o superiores, y Amparos Habitacionales, sobrevivientes que, por lo general no tienen redes sociales y familiares de apoyo, en su mayoría por ser migrantes internas o internacionales, y pertenecen a clases populares (Hasanbegovic y Otras, 2015).

La Constitución Nacional (artículo 14bis), las Convenciones Internacionales de Derechos Humanos (34) ratificadas por la Argentina, la Constitución de la CABA (artículos 17 y 31), la ley № 26.485 de Protección Integral a las Mujeres contra la Violencia, la ley No 26.061 de Protección Integral a Niñas, Niños y Adolescentes, y la ley No 3.706, de Protección Integral a las Personas en Situación de Calle de la CABA (que en su artículo 4 establece la obligación del Estado local de formular políticas públicas de vivienda) son las principales normas nacionales y locales que, tal como lo interpretó la Corte Suprema de Justicia de la Nación en el caso "Quisberth", instalan el derecho a la vivienda.

(32) OVD: Oficina de Violencia Doméstica de la Corte Suprema de Justicia de la Nación.

(33) Mujeres que residen en viviendas contiguas a las residencias de familiares y/o amigos de sus parejas, muchas veces en asentamientos precarios o villas de emergencia, donde para ingresar en su propia vivienda deben transitar por el interior de la vivienda de los familiares de su agresor, no piden la exclusión del hogar, pues no resulta práctico y seguro para ellas.

(34) Entre otros el artículo 25 de la Declaración Universal de Derechos Humanos, el artículo 11 del Pacto Internacional de Derechos Económicos, Sociales y Culturales, los artículos 27.1 y 27.3 de la Convención de los Derechos del Niño; la CEDAW; el artículo 8 inciso d) de la Convención Interamericana para Prevenir, Sancionar y Erradicar la Violencia contra la Mujer "Belém do Pará". 
La ley No 26.485 establece, por un lado, políticas públicas a cargo del Estado nacional, y por el otro, medidas de protección en cabeza del Poder Judicial. Las políticas públicas allí establecidas buscan fortalecer a las mujeres afectadas por la violencia y brindarles, entre otros recursos, alojamientos de emergencia seguros (artículo 10 inciso 6), y programas de asistencia económica (artículo 10 inciso 3), promoción de inserción laboral, asistencia integral, etc. (Título II, capítulo III). En tanto que, a través de las medidas judiciales (Título III, capítulo II) la ley No 26.485 establece el procedimiento, urgente, gratuito, y respetuoso de la dignidad de las mujeres, para obtener medidas preventivas que garanticen su seguridad. El artículo 26 dispone un menú de medidas a las que pueden acceder las mujeres afectadas por la violencia, incluyendo la exclusión del hogar, independientemente de la titularidad del inmueble (artículo 26, b.2), y el reintegro de la mujer que debió retirarse por la violencia, previa la exclusión de su agresor (artículo 26, b.3). Distintas evaluaciones han sugerido que el Estado argentino tiene grandes vacíos en materia de políticas públicas para prevenir, sancionar y erradicar la violencia contra la mujer, ya que no acompaña el trabajo del poder judicial en otorgar medidas de protección con acceso a vivienda, trabajo y empoderamiento económico (35) (ICEPCi y MuMaLá, 2015; ELA, 2012; Hasanbegovic, 2018). Sumado a este vacío, la inexistencia de un sistema de monitoreo sistemático del cumplimiento de las medidas de protección, el alto porcentaje de quebrantamiento de las medidas, y el patrón constante de la justicia penal de archivar las denuncias por amenazas y lesiones contra mujeres por sus parejas o ex parejas sin investigar los delitos denunciados (Hasanbegovic y otras, 2015; Hasanbegovic, 2018; ONU, 2017a; OVD, 2010; UFEM, 2018), hacen que la seguridad de las mujeres afectadas por violencia doméstica se encuentre verdaderamente comprometida.

\section{VI.1. Refugios/Casas de Medio Camino/Hogares de Protección Integral (HPI)}

El primer refugio para mujeres sobrevivientes de violencia de género en la pareja en la Argentina —en CABA — surgió hacia fines de los años 1990, y más de una década después se abrió una casa de medio camino en la Ciudad de Buenos Aires, donde en la actualidad existen un refugio y dos casas de medio camino (36).

(35) Escapa al límite de este trabajo evaluar el actual programa "Hacemos Futuro" del Ministerio de Salud y Desarrollo Social de la Nación, que reemplazó al anterior programa "Ellas Hacen". Consideramos, sin embargo, que éste no tiene la cobertura ni la sustentabilidad necesarias como para poder considerarse satisfechos los programas de asistencia económica específicos a los que alude la ley No 26.485.

(36) Son los refugios Mariquita Sánchez y las Casas de Medio Camino Juana Manso y Margarita Barrientos, y también existe un refugio para mujeres en alto riesgo víctimas de trata. La Ciudad de Buenos Aires también provee alojamiento para mujeres en situación de calle, donde también acuden mujeres afectadas por violencia de género (Hasanbegovic y otras, 2015). 
Estos dispositivos fueron creados y administrados por el Estado, existiendo unos pocos refugios administrados por iglesias en esos años. En 2017, el gobierno argentino informó a la Relatora de Violencia contra la Mujer de Naciones Unidas que "existían en el país un total de 87 refugios destinados a víctimas de violencia doméstica, así como otros administrados por organizaciones no gubernamentales" (ONU, 2017a, párr. 67), y que el Plan Nacional de Acción 2017-2019, "establece un presupuesto trienal, destinado en un $80 \%$ a la construcción de 36 hogares de protección integral (37) (refugios)" (ONU, 2017a, párr. 68; CNM, 2016, p. 88).

Según se desprende del Informe de Gestión 2018 del Instituto Nacional de las Mujeres - en adelante INAM - al 31 de diciembre de 2018 se habrían construido 9 de esos 36 HPI, y que

(...) se decidió un cambio de estrategia en la modalidad de trabajo con hogares priorizando llegar, en primer término, al fortalecimiento de aquellos hogares existentes y a organizaciones de la sociedad civil que trabajan en la materia para garantizar una atención integral, de conformidad con el Plan y con los nuevos modelos de atención a nivel mundial que se alejan de la lógica de refugios (38) y apuntan a la creación de espacios donde el foco este puesto en el empoderamiento de las mujeres en entornos cercanos a sus redes de contención. (...) se tornó necesario implementar, (...) el Programa "Red Nacional de Hogares de Protección Integral para Mujeres en Situación de Violencia”, el que tiene por finalidad financiar el equipamiento y/o las refacciones menores de HPI, ya existentes (...) (INAM, 2009, p. 27).

El informe de gestión no menciona los recortes presupuestarios que, a nuestro entender, han tenido peso en la decisión de "cambiar de estrategia", y hace alusión a "modelos de atención a nivel mundial que se alejan de la lógica de los refugios", que, como vimos más arriba al revisar las políticas Stay At Home Safe, son inefectivas al carecer de una respuesta judicial y policial positiva en frenar a los agresores y proteger a las sobrevivientes - como es el caso en Argentina-.

En 2018, los medios de difusión publicaron que "el presupuesto asignado para la lucha contra la violencia hacia las mujeres para el año 2019 asciende a $\$ 11,36$ por mujer al año" (Pavón, 2018, p. s/n). Dicho monto implica que "el Poder Ejecutivo recortó un $34,8 \%$ del presupuesto planeado para el INAM para el año 2019, lo cual representa una caída del $18 \%$ en términos reales en relación con el año anterior 2018" (ELA, s/f, p. 4). El ajuste presupuestario y la decisión de dejar de construir nuevos HPI van a contramano de la Convención Belém do Pará (artículo 8,

(37) En adelante HPI. Se trata de la Medida No 17 (CNM, 2016, p. 88).

(38) El resaltado me corresponde. 
inciso d, que establece la provisión de refugios) (OEA, 1995) y de las recomendaciones de organismos internacionales(39), en especial de la Relatora Especial de Violencia contra la Mujer, quien luego de visitar nuestro país recomendó "evaluar urgentemente la necesidad de abrir refugios y que haya suficientes refugios seguros en cada provincia, financiados por el Estado nacional o las provincias (...)" (ONU, 2017a, párrafo 88, d).

\section{VI.2. Acceso a vivienda a través de medidas judiciales}

Las mujeres afectadas por violencia de género en la pareja que residen en una vivienda propia, de su pareja, o de otra persona, pueden solicitar que su agresor sea excluido de la vivienda y quedarse ellas en la misma, por un período de tiempo que determinará el o la jueza que intervenga. Si bien la ley No 26.485 permite que cualquier juez de cualquier fuero e instancia dicte este tipo de medidas (artículo 21), en la práctica es la Justicia Nacional en lo Civil que se encuentra en la Ciudad Autónoma de Buenos Aires quien dispone las mismas con más asiduidad, y en un tiempo breve (40).

Entre el 15/09/2008 y el 31/12/2017, derivó a la Justicia Civil el 97\% de los 71.542 casos de mujeres que denunciaron violencia doméstica a la justicia civil, y el $79 \%$ de los mismos, a la justicia penal. (OVD, 2018a). Estas cifras son similares a lo informado en el primer año de funcionamiento de la OVD, para el período 15/09/2008 al 28/02/2010, se habían adoptado medidas de protección civiles en un $77 \%$ de los casos enviados, los que constituían el 90\% del total de casos (27.959). Las medidas otorgadas incluían: 1) prohibiciones de acercamiento (7.232 casos); 2) prohibiciones de contacto (1.666) y 3) exclusiones del hogar (1131 casos) (41) (OVD, 2010). En una investigación realizada sobre un universo de 3.254 expedientes iniciados por denuncias en la OVD, y una muestra de 115 expedientes seleccionados que tramitaron en 19 de los 24 juzgados Nacionales en lo Civil, se hallaron "datos coincidentes con los informados por la OVD en su primer año de funcionamiento" (ELA, 2012, p. 57).

Las cifras presentadas nos sugieren que las medidas cautelares de Exclusión Del Hogar combinadas con las Prohibiciones De Acercamiento constituyen una

(39) Sugieren la creación de refugios las recomendaciones generales números 19/1992 y 35/2017 del Comité CEDAW (ONU, 1992, 2017b); la Plataforma de Acción de Beijing (ONU, 1995-2014); los informes hemisféricos del Mecanismo de Seguimiento de la Implementación de la Convención Belém do Pará, a saber: Recomendación 15 en Planes Nacionales, y recomendación 36 en Presupuesto (OEA, 2017); y Recomendación 36 (OEA, 2012).

(40) Según lo informado por la OVD, en el $85 \%$ de los casos las medidas de protección fueron dictadas dentro de las 24 (OVD, 2017).

(41) El resaltado nos corresponde. 
forma de acceder a vivienda para mujeres sobrevivientes de violencia de género en la pareja. La seguridad de las mismas, sin embargo, dependerá del acatamiento de los agresores a las medidas cautelares, y de otros mecanismos de protección(42).

Otra forma de acceder a una vivienda cuando una mujer se ve obligada a dejar su hogar debido a la violencia de género y no puede regresar al mismo es mediante la obtención de subsidios habitacionales por 10 meses, y su prolongación hasta que se modifiquen las condiciones de vulnerabilidad en la que se encuentra (Hasanbegovic y Otras, 2015; CM, 2018). Esta prórroga se obtiene mediante la promoción de una acción de amparo habitacional en la Justicia Contencioso Administrativa y Tributaria (CAyT) de la CABA, generalmente con el patrocinio del Ministerio Público Tutelar de la CABA (CM, 2018), que, según sostiene el Defensor General del Poder Judicial de la Ciudad de Buenos Aires, ha "construido" la política pública habitacional desde el activismo judicial:

(...) hasta el día de hoy la Ciudad ha carecido de una política habitacional efectiva y consistente en materia de personas en situación de calle. Ante dicho vacío se había dictado diversos regímenes transitorios para subsanar la falta de aquella política (...). Esta experiencia judicial (...) una práctica jurídica sostenida en el tiempo donde hay una pluralidad de decisiones judiciales simultáneas y sucesivas, en un sistema de control difuso de constitucionalidad. Este panorama tiene que completarse con la jurisprudencia del Tribunal Superior de Justicia, que ha tenido una visión mucho más restrictiva de los derechos que los tribunales ordinarios. Dicha situación generó la intervención de la Corte Suprema de Justicia de la Nación (43), que dictó su primera sentencia sustancial sobre el derecho a la vivienda como consecuencia de la práctica jurídica porteña. (...) La remoción de la desigualdad persistente no es una opción moral o política, es un genuino deber constitucional que recae sobre todos los que cotidianamente construimos el sistema judicial porteño (44) (Horacio Corti en CM, 2017, p. 12).

(42) En muchos casos los juzgados ordenan a la Policía Metropolitana de la Ciudad de Buenos Aires proveer de un teléfono de contacto para las sobrevivientes; brindar botones antipánico a las mujeres y, en los casos identificados como de riesgo alto o altísimo para su vida por evaluación interdisciplinaria tanto de los equipos técnicos de la OVD como de la Oficina de Asistencia a la Víctima del Ministerio Público Fiscal de la CABA, pueden disponer consigna policial. Más recientemente, la Justicia Nacional en lo Criminal y Correccional ha ordenado la colocación de dispositivos de geoposicionamiento espacial a los agresores cuyos movimientos son monitoreados desde el Centro de Monitoreo y Gestión de la Subsecretaría del Ministerio de Justicia y Seguridad del Gobierno de la CABA (OVD, 2018b). La utilización de estos dispositivos está aún en su etapa inicial.

(43) Se trata del caso "Quisberth Castro, Sonia Yolanda c/GCBA s/Amparo [Artículo 14 CCABA] sentencia del 24/04/2012".

(44) El resaltado me corresponde. 
Las políticas sociales en la CABA y a nivel nacional ofrecen subsidios a personas en situación de desventaja, ya sea del tipo socio-económica (pobreza, falta de empleo, etc.), como física (discapacidad, edad avanzada, etc.) (Hasanbegovic y Otras, 2015; CM, 2018) (45). Estos subsidios son susceptibles a los cambios políticos de las administraciones de gobierno, a las crisis económicas y a las prioridades políticas para la determinación del presupuesto. Mientras las mujeres gestionan los subsidios y la obtención de un lugar donde alquilar que las acepten junto con sus hijos(as) menores, podrán estar alojadas en paradores para mujeres en situación de calle durante las horas nocturnas debiendo permanecer en la calle durante el día, o bien en el refugio para sobrevivientes de violencia doméstica (Hasanbegovic y Otras, 2015). Las condiciones del refugio son de encierro total por varios meses para seguridad de la mujer que accede y de todas las demás residentes den el refugio (Hasanbegovic, 2012).

En el caso "Quisberth", la CSJN (46) ha decidido que debido a la falta de política pública habitacional en la Ciudad de Buenos Aires, y a lo inadecuado de los subsidios habitacionales existentes la Ciudad no garantizaba adecuadamente el derecho a vivienda de una mujer y su hijo, a pesar que el TSJ (47) de la Ciudad había concluido, en la sentencia recurrida, "que el gobierno local satisfacía el derecho a la vivienda de los reclamantes a través de las redes de albergues y paradores nocturnos y, por lo tanto, rechazaba los amparos en esta materia" (Tedeschi, 2015, p. 160). En su revisión de dicho fallo, la CSJN recordó las propias declaraciones del gobierno de la Ciudad en el expediente que sostuvo que "No hay programas de vivienda para personas en situación de calle" (párr. 13º) (Tedeschi, 2015, p. 161) y agregó que

(...) los paradores tampoco resultan suficientes en número para albergar, siquiera transitoriamente, al total de las personas sin techo de la Ciudad de Buenos Aires. Según los dichos de la propia demandada, existen 7 paradores estatales, más otros tantos privados con los que el Estado local tiene convenio. Estos cuentan, aproximadamente, con un total de 1.600 plazas. Sin embargo, son 7.000 las personas por año que solicitan el subsidio, de las que actualmente 4.500 están cobrando el beneficio por haber acreditado carecer de ingresos suficientes para

(45) En Hasanbegovic y otras (2015) se puede leer un detalle pormenorizado de los subsidios que podía solicitar a 2015 una mujer sobreviviente de violencia doméstica en la CABA, ya fuera al Estado Nacional o al Gobierno de la CABA, conforme surgen de los portales de internet de los Ministerios de Desarrollo Social de ambas jurisdicciones. Para una lectura actualizada de los subsidios existentes a 2017, ver: CM (2018), protocolo en el que trabajé como consultora. Se observó que no existía subsidio específico a su situación de violencia.

(46) CSJN: Corte Suprema de Justicia de la Nación.

(47) TSJ: Tribunal Superior de Justicia de la CABA. 
costear una vivienda (Considerando $14^{\circ}$, voto Dr. Petracchi, citado en Tedeschi, 2015, p. 162).

Este fallo brinda importantes lineamientos para el acceso a la vivienda en la Ciudad de Buenos Aires, estableciendo que: "a) el derecho a la vivienda es un derecho operativo, es decir, auto exigible para todos; b) las políticas públicas en materia de derechos sociales son revisables judicialmente, y c) los límites presupuestarios no sirven de excusa para incumplir los derechos sociales" (Tedeschi, 2015, pp. 165-169).

Específicamente en materia de violencia de género y acceso a la vivienda en la Ciudad Autónoma de Buenos Aires, desde el fallo del TSJ “Sztern”, el Estado local debe proveer alojamiento a determinados grupos vulnerables, entre los cuales las mujeres víctimas de violencia de género se encuentran entre aquellas personas que deben recibir mayor protección habitacional, en virtud de toda la normativa internacional, nacional y local que regula este derecho. En especial, mencionó el Tribunal, el artículo 20 de la ley No 4036 de la ciudad, que expresamente establece la obligación del gobierno de la Ciudad de proveer albergue a las mujeres y sus hijos/as que se encuentren en situación de calle debido a la violencia doméstica.

\section{Conclusión y recomendaciones}

En este artículo hemos visto que los refugios y casas de medio camino surgieron desde las propias sobrevivientes de violencia de género en la pareja, a partir de la necesidad de contar con una opción de vivienda segura para dejar a sus agresores. Sus comienzos en los años 1970s fueron políticos y emancipatorios, y luego pasaron por procesos de institucionalización, profesionalización y cooptación en los países donde surgieron. En la década de los años 1990s desde el Comité CEDAW se recomendó a todos los gobiernos la implementación de los dispositivos habitacionales de emergencia y de medio camino, como parte del menú de respuestas a las mujeres afectadas por la violencia de género en la pareja. Fue así que en América Latina comenzaron a surgir los primeros refugios o casas abrigo. La injusticia de tener que dejar la propia morada a su agresor a fin de salvar la vida es incuestionable; sin embargo, ante la persistencia de respuestas policiales y judiciales inefectivas para frenar a los hombres violentos y prevenir futuros ataques a las sobrevivientes, estos dispositivos habitacionales continúan siendo necesarios y deben constituir una opción que pueda elegir la mujer sobreviviente.

En el contexto latinoamericano, consideramos que para que estos dispositivos habitacionales de respuestas a la violencia de género en la pareja sean exitosos, deben considerar que trabajarán con una población extremadamente vulnerable debido a la intersección de múltiples discriminaciones; deben brindar a las 
sobrevivientes - y a sus hijos e hijas- asistencia jurídica, psicológica, y social. Además, es necesario impartir talleres para facilitar su comprensión del patriarcado, los estereotipos sexistas, la violencia de género, las dinámicas del maltrato, y las consecuencias que éste ha causado en sus vidas. Al mismo tiempo, se requiere proveer a las mujeres una capacitación laboral en oficios que les permitan una rápida salida laboral (48). Todo ello deberá ser realizado con compromiso, creatividad y flexibilidad - tanto en las normas de convivencia dentro de los refugios y casas de medio camino, como en los plazos de estadía - y contando con la participación de las mujeres y sus hijos/as en la formulación de las políticas del dispositivo habitacional.

Se recomienda que estas políticas hacia el interior de los dispositivos habitacionales específicos sean acompañadas de políticas públicas que fomenten el empoderamiento económico de las mujeres en general y, específicamente, para aquellas que dejan relaciones de pareja violentas, brinden subsidios o facilidades para obtener trabajos remunerados, y ayudas para acceder al alquiler $-\mathrm{o}$ compra- de viviendas. Esto requiere presupuesto adecuado sostenido en el tiempo, y un mayor compromiso del Estado en el cumplimiento de las obligaciones asumidas en los tratados y convenciones internacionales, en la ley No $26.485-$ a nivel nacional-, y demás normas a nivel local. A nivel judicial, el compromiso del Estado necesita modificar la respuesta de la justicia penal y civil, y de las fuerzas policiales, para monitorear y garantizar efectivamente la protección de las mujeres que acuden al mismo para frenar la violencia y prevenir su reiteración.

En el ámbito de la CABA, hasta que no se efectivicen los cambios sugeridos de acuerdo con los estándares internacionales de derechos humanos en este campo, las medidas cautelares en la Justicia Nacional en lo Civil, y los amparos judiciales en la Justicia CAyT seguirán siendo las principales formas de acceder a vivienda para las mujeres que quedan en situación de calle o en peligro de estarlo como consecuencia de la violencia de género en la pareja.

\section{Bibliografía}

Ávila Jácome, P. (2012). Modelo de Atención de Casa de Acogida para Mujeres que Viven Violencia. Quito: ACNUR.

CEPAL (2016). Autonomía de las mujeres e igualdad en la agenda de desarrollo sostenible. Santiago: Naciones Unidas.

(48) Dado que en nuestras sociedades los oficios tradicionalmente "masculinos" (como por ejemplo, albañilería, plomería, electricidad, gasista, choferes) son mejor remunerados que los tradicionalmente "femeninos" (por ejemplo, trabajo de empleada doméstica, cocineras, niñeras, etc.), sugerimos que se capacite a las mujeres en el primer tipo de oficios. 
Ciudad Autónoma de Ceuta (2013). Reglamento de Pisos Tutelados para Mujeres Víctimas de Violencia de Género. Ceuta. Recuperado de http://www.ceuta.es/ ceuta/la-institucion/normativa/46-paginas/paginas/normativa/158-reglamento-de-pisos-tutelados-para-mujeres-victimas-de-violencia-de-genero [Fecha de consulta: 18/08/2018].

Ciapessoni, F. (2014). Informe: Situación de calle desde una perspectiva de género y el trabajo de atención directa. Recuperado de https://ladiaria.com.uy/media/ attachments/Informe_mujeres_Fiorella_Ciapessoni_1.pdf [Fecha de consulta: 18/08/2018].

CMHC (2007). Shelter Enhancement Program 2007 Evaluation Plan. Canada: Mortgage and Housing Corporation.

CMHC (2009). Final Evaluation Report on the Shelter Enhancement Program (SEP). Canada: Mortgage and Housing Corporation.

Commonwealth of Australia (2000). Home Safe Home. The Links between domestic and family violence and women's homelessness. Gobierno de Australia.

Commonwealth Of Australia (2008). The Road Home. A National Approach to Reducing Homelessness. Recuperado de https://www.abc.net.au/cm/lb/4895838/ data/the-road-home---a-national-approach-to-reducing-homelessness-data.pdf [Fecha de consulta: 30/08/2018].

CNM (2016). Plan Nacional de Acción para la Prevención, Asistencia y Erradicación de la Violencia contra la Mujer (2017-2019). Consejo Nacional De Las Mujeres - Consejo Nacional de Coordinación de Políticas Sociales, Presidencia de la Nación. Recuperado de https://www.argentina.gob.ar/sites/default/files/ consejo_nacional_de_mujeres_plan_nacional_de_accion_contra_violencia_genero_2017_2019.pdf [Fecha de consulta: 30/08/2018].

CM (2018). Primera Línea de Acción. Protocolo de Intervención para el Acceso a Justicia a Mujeres en Situación de Violencia de Género en las Relaciones de Pareja. CABA: Consejo de la Magistratura de la Ciudad de Buenos Aires.

Correia, A. y Melbin, A. (2005). Transitional Housing Services for Victims of Domestic Violence, A Report from the Housing Committee of the National Task Force to End Sexual and Domestic Violence. Recuperado de https://vawnet.org/sites/ default/files/assets/files/2016-09/TransHousingServices.pdf [Fecha de consulta: $15 / 01 / 2019]$.

Dale, A. (2009). Phase III Project. Beyond Shelter Walls. Discussion Paper No More Running in Circles. Ontario: YWCA. 
DGM (2011a). Protocolo de Atención en Casas de Medio Camino. CABA: Dirección General de la Mujer del Gobierno de la Ciudad de Buenos Aires. Ministerio de Desarrollo Social.

DGM (2011b). Protocolo de Atención en Refugio para Mujeres Maltratadas. CABA: Dirección General de la Mujer del Gobierno de la Ciudad de Buenos Aires. Ministerio de Desarrollo Social.

Dobash, R. y Dobash, R. (1980). Wife Battering: A case against Patriarchy. Londres y Nueva York: Routledge.

Dobash, R. y Dobash, R. (1992). Women, Violence and Social Change. Londres - Nueva York: Routledge.

Edwards, R. (2004). Staying Home/Leaving Violence. Promoting choices for women leaving abusive partners. Recuperado de http://pandora.nla.gov.au/ pan/75474/20070806-1337/www.austdvclearinghouse.unsw.edu.au/PDF\%20files/SHLV.pdf [Fecha de consulta: 10/08/2018].

ELA (2012). Más allá de la denuncia. Los desafíos del acceso a la Justicia. Buenos Aires: Equipo Latinoamericano de Justicia y Género.

ELA (s/f). Análisis del Proyecto de presupuesto 2019 desde una perspectiva de género: avances y retrocesos para la igualdad. 16 Días de Activismo [2018]. Buenos Aires: Equipo Latinoamericano de Justicia y Género. Recuperado de http://www. ela.org.ar/a2/index.cfm?muestra\&codcontenido=3600\&plcontampl=12\&aplicaci on=app187\&cnl=4\&opc $=47$ [Fecha de consulta: 01/03/2019].

Frederick, L. M. y Lizdas, K. C. (2003). The Role of Restorative Justice in the Battered Women's Movement. Minneapolis: Battered Women`s Justice Project.

Gaddis, P. (2006). A creation story of battered women's shelter. En Koyama, E. (2006). Disloyal to feminism. Recuperado de http://eminism.org/readings/pdfrdg/disloyal.pdf [Fecha de consulta: 15/03/2019].

Gregory, R. (2001). Revisting domestic violence and homelessness. En The Domestic Violence and Incest Resource Centre, the Council of Homeless Persons (ed.), Out of the Fire: Domestic violence and homelessness (pp. 13-14). Melbourne: Domestic Violence and Incest Resource Centre and Council for Homeless Persons.

Hasanbegovic, C., Oliva, R. B., y Cymerman, C. (2015). Varones violentos/Estado Negligente. El tortuoso camino de exigir alimentos para los hijos/as en CABA. En M. E. Lanari, y C. Hasanbegovic (comp.), Mujeres de Latinoamérica, el presente en veintidós letras (pp. 53-100). Mar del Plata: EUDEM. 
Hasanbegovic, C. (2018). Respuestas judiciales y otras políticas públicas sobre violencia contra las mujeres. ¿Ineficacia o violencia institucional? En Anales Revista de la Facultad de Ciencias Jurídicas y Sociales, Universidad de La Plata, volumen (48) 15 (pp. 1161-1205).

Hasanbegovic, C. (2014). Informe de consultoría: Asistencia Técnica Especializada para el Diseño de una Guía de Instalación para Casas de Medio Camino para Mujeres en Situación de Violencia Doméstica. Montevideo: Instituto Nacional de las Mujeres. Ministerio de Desarrollo Social.

Hasanbegovic, C. (2012). Violencia de Género en la Ciudad Autónoma de Buenos Aires. El Reporte Judicial, Tribunal Superior de Justicia de Chubut, No 27 (pp. 87-100).

Hasanbegovic, C. (2010). Fronteras del odio. Violencia de género contra mujeres Latinoamericanas en Londres y Buenos Aires. En Y. Delgado de Smith, y M. C. González (comp.), Mujeres en el Mundo (pp. 101-116). Carabobo, Valencia: Universidad de Carabobo.

Instituto Nacional de Las Mujeres -INAM- (2019). INAM Gestión 2018. Recuperado de https://www.argentina.gob.ar/sites/default/files/informedegestion2018. pdf [Fecha de consulta: 3/03/2019].

INDEC (2019). Registro Único de casos de violencia contra las mujeres - RUCVM: resultados 2013-2018. Ciudad Autónoma de Buenos Aires: Instituto Nacional de Estadísticas y Censos. Recuperado de https://www.indec.gob.ar/uploads/informesdeprensa/rucvm_03_19.pdf [Fecha de consulta: 20/03/2019].

INMUJERES (2008). Guía Metodológica para la Sensibilización en Género: Una herramienta didáctica para la capacitación en la administración pública. Vol. 1. México D.F.: Instituto Nacional de las Mujeres.

INMUJERES (2013). Protocolo de Casa de Breve Estadía Para Mujeres en situación de riesgo de vida por violencia doméstica. Montevideo: Instituto Nacional de las Mujeres. Ministerio de Desarrollo Social.

Koyama, E. (2006). Disloyal to Feminism: Abuse of Survivors within the Domestic Violence Shelter System. Recuperado de http://eminism.org/readings/pdf-rdg/ disloyal.pdf [Fecha de consulta: 15/03/2019].

Krueg, E. G. y Otros (2002). World Report on Violence and Health. Ginebra: World Health Organization. 
Organización de Estados Americanos -OEA- (1995). Convención Interamericana para Prevenir, Sancionar y Erradicar la Violencia contra la Mujer "do Belém do Pará". Recuperado de http://www.oas.org/juridico/spanish/tratados/a-61.html [Fecha de consulta: 15/03/2019].

Organización de Estados Americanos -OEA- (2012). Segundo Informe Hemisférico. Washington: Mecanismo de Seguimiento de la Implementación de la Convención Interamericana para Prevenir, Sancionar y Erradicar la Violencia contra la Mujer. Recuperado de http://www.oas.org/es/mesecvi/docs/MESECVI-SegundoInformeHemisferico-ES.pdf [Fecha de consulta: 15/03/2019].

Organización de Estados Americanos -OEA- (2017). Tercer Informe Hemisférico. Mecanismo de Seguimiento de la Implementación de la Convención Interamericana para Prevenir, Sancionar y Erradicar la Violencia contra la Mujer. Recuperado de http://www.oas.org/es/mesecvi/docs/TercerInformeHemisferico-ES. pdf [Fecha de consulta: 15/03/2019].

Mbilinyi, L. y Kreiter, A. (2013). The Washington State Domestic Violence Housing First Program. Evaluation Summary. Seatle: WSCADV.

ICEPCi y MUMALÁ (2015). Deudas pendientes en la eliminación de la violencia contra las mujeres en la Argentina. Recuperado de http://www.parlamentario. com/db/000/000141_monitoreo.pdf [Fecha de consulta: 30/08/2018].

Meyer, N. J. (2006). Now you see it, now you don't: the state of the battered women movement. En E. Koyama (ed.), Disloyal to feminism: Abuse and Survivors within the Domestic Violence Shelter System. Color of Violence An INCIDTE! Anthology. Recuperado de http://eminism.org/readings/pdf-rdg/disloyal.pdf [Fecha de consulta: 15/03/2019].

Novac, S., Brown, J. y Bourbonnais, C. (2009). Transitional Housing Models in Canada: Options and Outcomes. En D. Hulchanski, Finding Home, Policy Options for Addressing Homelessness in Canada. Capítulo (1.1) Recuperado de http://carrieresantementale.ca/Resource\%20Library/Housing\%20and\%20Community\%20Reintegration/Transitional\%20Housing\%20Models\%20in\%20Canada\%20-\%20Options\%20and\%20Outcomes\%20-\%202009.pdf [Fecha de consulta: $15 / 08 / 2018]$.

O'Connor, M. (2006). Housing Policy and Practice for Women Experiencing Domestic Violence. Recuperado de https://www.womensaid.ie/download/pdf/housing_policy_practice_women.pdf [Fecha de consulta: 10/08/2018].

O'Connor, M. y Wilson, N. (2004). Safe Home, SONAS Housing Association Model of Supported Transitional Housing. Dublin: SONAS Housing Association. 
Olson, L. (2007). Battered Women's Shelter: Reflections. Washington State Coalition Against Domestic Violence.

Oficina de Violencia Doméstica -OVD- (2018a). Acceso a Justicia. 8 de Marzo. Día Internacional de la Mujer. (Período 2008-2017). OVD. Corte Suprema de Justicia de la Nación. Recuperado de http://www.ovd.gov.ar/ovd/ verMultimedia?data=2121 [Fecha de consulta: 10/03/2019].

Oficina De Violencia Doméstica -OVD—(2018b). Violencia de género: la justicia ordenó la colocación de un dispositivo de geoposicionamiento para proteger a la mujer. OVD. Corte Suprema de Justicia de la Nación, 10/08/2018. Recuperado de http://www.ovd.gov.ar/ovd/verNoticia.do?idNoticia=2387 [Fecha de consulta: $10 / 03 / 2019]$.

Oficina de Violencia Doméstica -OVD- (2017). OVD: El 85\% de las medidas de protección dictadas por la justicia Nacional en lo Civil se otorgó dentro de las 24 horas posteriores a la denuncia. Recuperado de http://www.ovd.gov.ar/ovd/verNoticia.do?idNoticia=2072 [Fecha de consulta: 10/03/2019].

Oficina de Violencia Doméstica -OVD- (2010). Estadísticas en el primer año de funcionamiento de la OVD, 15/9/2008-28/2/2010. Buenos Aires: OVD. Corte Suprema de Justicia de la Nación.

Organización de las Naciones Unidas - ONU— (2017a) A/HRC/35/30/Add.3. 35. 12 de abril de 2017. Consejo de Derechos Humanos, $35^{\circ}$ Período de sesiones. En Informe de la Relatora Especial sobre violencia contra la Mujer, sus c causas y sus consecuencias Sra. Simonović, D. relativas a su misión a la Argentina. Recuperado de http://acnudh.org/wp-content/uploads/2017/08/mujer.pdf [Fecha de consulta: 5/02/2019].

Organización de las Naciones Unidas - ONU— (2017b) Recomendación general No. 35 sobre violencia basada en el género contra las mujeres, actualización de la recomendación general 19/92. CEDAW/C/GC/35, 14 de julio de 2017. Recuperado de https://www.acnur.org/fileadmin/Documentos/BDL/2017/11405.pdf [Fecha de consulta: 15/02/2019].

Organización de las Naciones Unidas - ONU- (2005). Estudio "La Mujer y la Vivienda Adecuada", del señor Kothari, M. Relator Especial sobre una Vivienda adecuada como elemento integrante del derecho a un nivel de vida adecuado. E/ CN.4/2005/43. Naciones Unidas.

Organización de las Naciones Unidas -ONU- (1995-2014). Declaración y Plataforma de Acción de Beijing - Declaración política y documentos resultados de 
Beijing. Recuperado de http://feim.org.ar/wp-content/uploads/2017/05/Beijing Doc.pdf [Fecha de consulta: 15/02/2019].

Organización de las Naciones Unidas - ONU- (1992) Recomendación general No 19/1992 sobre violencia contra las mujeres, A/46/38, 14 de julio de 2017. Recuperado de https://tbinternet.ohchr.org/Treaties/CEDAW/Shared\%20Documents/1_Global/INT_CEDAW_GEC_3731_S.pdf [Fecha de consulta: 15/02/2019].

Pahl, J. (1978). A Refuge for Battered Women: A Study of the Role of a Women's Centre. Londres: Her Majesty's Stationery Office.

Pavón, M. L. (2018). Presupuesto 2019: \$ 11 por mujer para prevenir la violencia de género, Tiempo Argentino. Recuperado de https://www.tiempoar.com.ar/nota/ presupuesto-2019-11-por-mujer-para-prevenir-la-violencia-de-genero [Fecha de consulta: 10/03/2019].

Ricciardi, V. (2010). El derecho a la vivienda como elemento imprescindible para vivir una vida libre de violencia doméstica. Los casos de Argentina, Brasil y Colombia. En Congreso Internacional: Las Politicas de Equidad de Género en Prospectiva. Buenos Aires: FLACSO. Recuperado de http://www.prigepp.org/ congreso/documentos/ponencias/1_Victoria_Ricciard.pdf [Fecha de consulta: $10 / 08 / 2018]$.

SERNAM (2013). Orientaciones Técnicas 2013. Modelos de Intervención en Terreno. Programa Chile Acoge. Santiago de Chile: Servicio Nacional de la Mujer.

Sharp, N. (2008). What is yours is mine. The different forms of economic abuse and its impact on women and children experiencing domestic violence. Londres: Refuge.

Sullivan, C., Melbin, A. y Cain, D. (2003). Transitional Housing Policy and Practices: Battered Women's and Service Provider's Perspectives. Recuperado de https:// vawnet.org/sites/default/files/materials/files/2016-09/TransHousPolicy.pdf [Fecha de consulta: 10/08/2018].

Tedeschi, S. (2015). Construyendo Vivienda como Derecho Exigible. En Poder Judicial de la Ciudad de Buenos Aires, Consejo de la Magistratura (comp.), Quince Años, Quince Fallos. En conmemoración de la creación del fuero Contencioso Administrativo y Tributario de la Ciudad Autónoma de Buenos Aires (pp. 157-170). Buenos Aires: Jusbaires Editorial.

Tutty, L., Ogden, C. y Weaver-Danlop, G. (2008). An Environmental Scan of Strategies to Safely House Abused Women. Alberta: University of Calgary. 
Tutty, L. (2006). Effective Practices in Sheltering Women Leaving Violence in Intimate Relationships. Phase II. Report 2006. Ontario: YWCA.

UFEM (2018). La violencia contra las mujeres y la justicia penal. Dirección General de Políticas de Género. Argentina: Ministerio Público Fiscal de la República Argentina.

Vargas Escobar, M. y Mejía Palma, Y. (2012). Albergues de Nicaragua "Un lugar seguro para cada mujer". Proyecto Atención Integral a Víctimas de Violencia de Género. Managua: AECID y OEI.

\section{Legislación}

Constitución Nacional. Boletín Oficial de la República Argentina, Buenos Aires, 10/01/1995.

Constitución de la Ciudad Autónoma de Buenos Aires. Boletín Oficial de la Ciudad de Buenos Aires, Buenos Aires.

Ley No 26.485. Boletín Oficial de la República Argentina, Buenos Aires, 14/04/2009.

Ley No 24.430. Boletín Oficial de la República Argentina, Buenos Aires, 3/01/1995.

Ley No 3.706. Boletín Oficial de la Ciudad de Buenos Aires, Buenos Aires, 08/06/2011.

Ley No 4.630. Boletín Oficial de la Ciudad de Buenos Aires, Buenos Aires, 13/08/2013.

\section{Jurisprudencia}

Fallos 335:452.

TSJ, 15-04-2014, "Sztern María Eugenia s/queja por recurso de inconstitucionalidad denegado Sztern, María Eugenia c/GCBA y otros s/amparo (artículo 14 CCABA) Expte. No 9814/13".

Fecha de recepción: 03-04-2019

Fecha de aceptación: 27-09-2019 
